\title{
Applying an Arabic Conversational AgENT IN THE JORDANIAN E-GOVERNMENT
}

\author{
Mohammad Hijjawi and Hesham Abusaimeh \\ Department of Computer Science, Applied Science University, Amman, Jordan
}

\begin{abstract}
This paper discusses a prototype idea of applyinga Conversational Agent (CA) to be embedded into the Jordanian E-government websites. The Conversational Agent is a smart system used to handle natural conversations between user and machine. A Jordanian citizen facing struggles when he/she want to apply for a service through the E-government portal.In addition the Jordanians struggling when searched for a piece of information (for example the needed documents for a specific service) inside the E-government websites. This struggling comes from number of reasons such as the needed knowledge that the user could have to deal with such services and the big number of links that the user must visitto achieve his/her target. In addition, the Jordanian E-Government websites does not meet the users' requirements in their design. Instead, this paper proposes the idea of applying a prototype called CA into those websites as a general helpdesk automated service to save the Jordanians time and effort. Simply, the user will chat with the proposed CA with what he/she coming to do through the targeted website using a text based Arabic conversations. The CA's responses might be the exact needed link or the targeted information. Such a proposed service will strength the Jordanian E-government platform especially for accessibility and usability factors and as to best of our knowledge, no country has been applied it before.
\end{abstract}

\section{KEYWORDS}

Electronic government, Jordan, usability, accessibility and Conversational Agent.

\section{INTRODUCTION}

Nowadays, the Information and Communication Technology (ICT) revolution affected the people life in many aspects. This revolution has been accepted by us and by our governments to encourage changes in our daily life facets [1]. In addition, this revolution changes the interaction way that governments adopt with their citizens, businesses, employees, government agencies, and other stakeholders [2]. These changes introduced a new discipline which is Electronic Government (E-Gov). E-Gov is a way that used to automate and enhance the access to a government information and to accelerate the government services delivery to citizens, businesses, their employees and other agencies [1].To this end, number of governments have been inspired by the E-Gov abilities to enhance their quality of services and to reduce operating costs for all parties (the government, businesses and citizens)[1]. Generally, it increases the efficiency in the public sector organisations [3][1].

People needs and government ambition were the best drivers for E-gov services creation. As mentioned above, number of governments and a lot of studies has been discussed the E-gov's framework according to different aspects. All of this attention is because the importance of an EGov project for countries. Jordan was one of those countries who concerns about the E-Gov and it has the fourth rank among the Arab countries according to [4].The E-Gov in Jordan was announced as a national program in 2001 by his Majesty King Abdullah II and the actual 
implementation was in 2003 under the name "Jordan E-government Program". The E-Gov Portal (Jordan.gov.jo), launched in September 2006 [4]. Where the first official document from the Jordanian government that presents the strategy for development and implementation of E-Gov is from the period of 2006 until the end of 2009 [5]. The E-Gov in Jordan has a clear vision as it is adopted to deliver its services to people regardless of their location and to enhance the economic and the ICT sector ability. Besides that the Jordanian government focused on a customer-centric approach, it is will contribute to the Jordanian economic and social development in general [5].The objective of the E-Gov project was to increase the overall governmental services quality and improving its efficiency by reducing time, cost and user's effort. In addition, the Jordanian EGov project seeks to achieve a good customer satisfaction with high transparency and crossgovernment integration [2]. Generally, this will contribute to the relationship among all participated parties such as government, businesses and citizens.

The Jordanian E-Gov provides different types of services classified by the service's beneficiary such as [5]:

1) G2C (Government to Citizen) services, which it targeting citizens such as e-Tax.

2) G2B (Government to Business) services, which it targeting businesses such as online business registration.

3) G2G (Government to Government) services, which it targeting government entities such as government publications.

4) G2E (Government to Employee) services, which it targeting government employees such as e-payroll.

According to the E-Gov survey of national and Jordanian ministerial websites that has been reported by United Nations in 2010 [6], the Jordanian E-Gov utilisation percentage of service delivery passing through five stages. Stage 1 is "Emerging" and has $80 \%$ of utilisation, stage 2 is "Enhanced" with $67 \%$ of utilisation and stage 3 is "Interactive" with $78 \%$ of utilisation. Where, stage 4 which is "Transactional" has $19 \%$ of utilisation and stage 5 "Connected" has $9 \%$ of utilisation [6]. According to this report, low percentages of stages 4 and 5 which means still the Jordanian E-Gov not providing transactional/connecting services to people. As a result, the Jordanian E-Gov project is still can be considered in the informative stage [7], which means it only provide users with information about services such as contact numbers, downloading documents or a general description of a service [7]. According to [2], the Jordanian E-Gov project is still between stages 2 and 3 as appeared in Figure 1 .

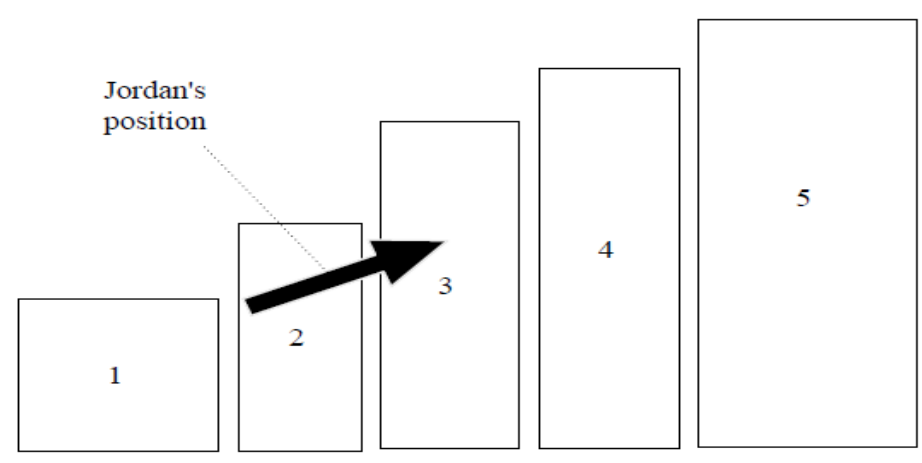

Figure 1: The Position of E-Gov in Jordan (taken from [2]) 
The wide vision of an E-Gov classifications and services project which listed before for a country will leads the government for such country to face challenges to achieve the final target. According to [2, 4, 8-11], the Jordanian government faces number of challenges such as:

- It is difficult to adapt the technology with the development of laws and legislation.

- Increasing the technological progress rapidly.

- The lack of qualified human resources.

- From the culture perspective, the struggling to change at all operational levels.

- Low Internet usage and penetration.

- The bureaucratic hierarchy in Jordanian ministries.

- Security and privacy concerns.

- Lack of citizen awareness in such services.

- Lack of the available budget for e-government deployment.

- Usability.

- Accessibility.

The Jordanian government has been faced number of challenges as listed above. However, this paper's objective is not to evaluate or discuss the Jordanian E-Gov weaknesses and challenges. In this paper, only two of the above challenges will be discussed which are usability and accessibility challenges to cover the paper's scope and to show the benefits of embedding a CA inside the Jordanian E-Gov portal platform as the next sections describe.

\section{Usability and Accessibility in the Jordanian E-Gov Websites}

The ISO (International Organisation for Standardization) defines the term usability as "the extent to which a product can be used by specified users to achieve specified goals with effectiveness, efficiency and satisfaction in the specified context of use" [12].In addition, the usability can be defined in the web usability context as set of factors that should be taken into consideration when design a website in order to allow users to perform their tasks easily such as simplicity, clarity and consistency[13]. According to [14], the web usability can be defined as how much the user interfaces is easy to use.

According to the above usability definitions, a user might leave a website (based on its architecture design) if it was difficult to use, difficult to read information, cannot get answers to his/her questions or unusable in general [8].In the paper's scope, leaving an E-Gov website might means failing the website of offering services and thus might be lead to fail the E-Gov program in general. According to [15], there are number of factors that lead a user to revisit or un-revisit a website which mainly depends on several metrics such as ease of use, minimum download time, and often update and high quality content. In addition, a user has a small level of patience if a website was slow or has difficult design [15]. Moreover, most users start scanning the first page of a website to find the useful link for their targeted service/information, therefore, the most important thing in usability is to make a good design for the homepage of any website [16]. Generally, the usability is not only how the website works well, but also it how much the website meets customer needs [17]. Meeting the customer needs should be designed to reflect an easy understanding of the website's structure [18]. The user looks for a well-organised website, straightforward and clears [8]. One of the principles that make a user to decide to use a website is not only the usability but quality of the usability [8]. The presented information should be useful, readable, brief and not boring [8]. The website appearance is an important factor as it should appeared visually attractive [8]. A good usable website should contain a search tool facility to facilitate the customers' tasks with the minimum time/effort to achieve their goal. 
According to [19-22], the usability still considered as one of the main problems that struggling users of E-Gov websites in many countries. A poor usability in E-Gov websites development it will affects the failure of electronic government project [8]. A good level of usability measurement of an E-Gov website is not depend on the number of services of such a website provides, but it depends on meeting the user needs and their expectations. According to [23],"a website that is not usable is useless". In E-Gov projects in most developing countries, there is a gap between the design and reality in the developed websites which it is behind a failure of such projects [24].

In Jordan, the insufficient development of E-Gov project was one of the main reasons behind not achieving the project objectives [10]. The majority pf agencies who working on developing the EGov projects were focused on the electronic service delivery rather than considering the user needs such as effectively navigation the website and ease of use [7, 8].Some of the municipalities websites usability has been examined around the world including Jordan in[25]. In this study[25], number of elements has been used to measure/examine the usability such as user-friendly design and website search capabilities(offering a search tool). The resulted usability of the Amman municipality website is $62 \%$. The mentioned study concluded that this result $(62 \%)$ is not good enough and it need further focusing on the website usability metrics.

Another study has been examined the usability in E-Gov websites in Jordan, and the reported results showed that a low usability status with average 29\% [26]. In this study [26], six dimensions of E-Gov websites has been taken into considerations depending on another study [27] as shown in Figure 2. The selected dimensions included accessibility accommodations, online services, legitimacy, information architecture, ease of navigation and user help provided [27].

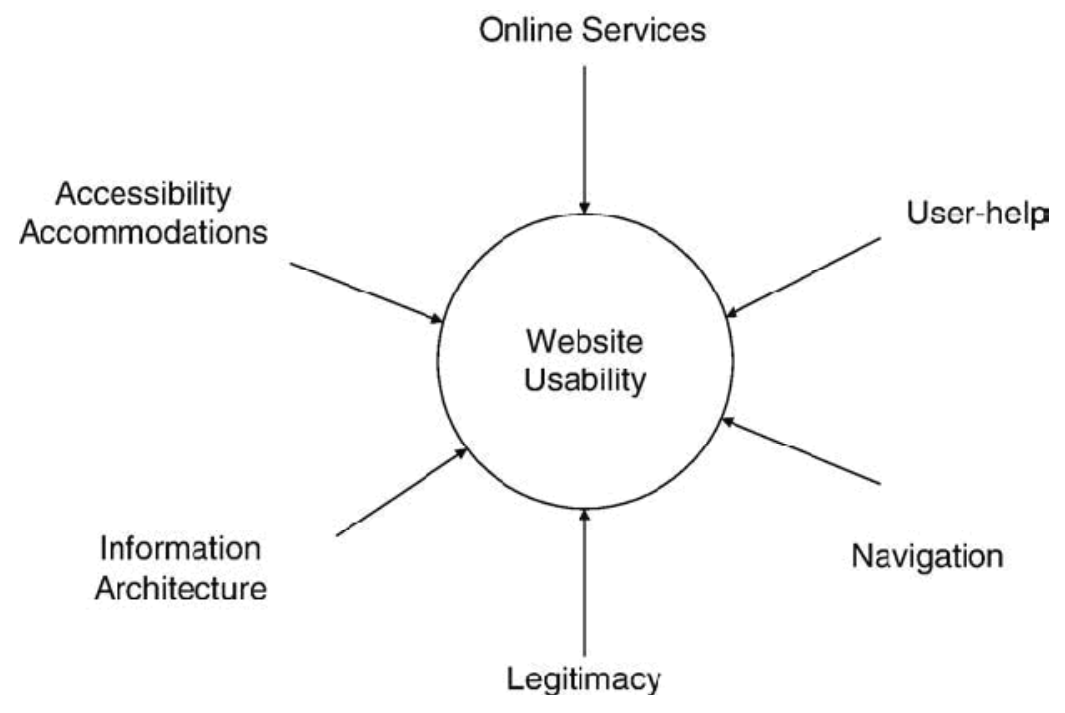

Figure 2: Website Usability Dimensions (taken from [27]).

According to the study [26], the development of Jordanian E-Gov websites ignored the Jordanian people needs and did not meet the users' expectations. As a result, there is a gap between the users and e-services with a poor websites design (not user friendly and hard to navigate). In addition, the construction of the websites was weak as it indicates to a low level of understanding for the basic standards of E-Gov services [26].Another study conducted by [10] to examine the Jordanian E-Gov websites depending on their usability, transparency, accessibility and responsiveness to citizens' request. In this study, presence of 12 features has been checked and 
examined manually in different websites to conclude that there is a big lack of consistency in the design standards. Additionally, the study revealed that there is a lack of consideration of users' needs and their expectations [10].

From other side, another study [8] discussed the usability for the Jordanian E-Gov services from the management perspective rather than from the end-user perspective. This study had to investigate the level of usability understanding and awareness of the current Jordanian E-Gov services professionals whose in charge of managing E-Gov projects from different institution [8]. Like such investigating will show the source causes of the current usability problems [8]. The study relied on administration based questionnaire to be distributed to 37 managers from different E-Gov services based institutions. The study participants' ages were between 22 to 65 years $(76 \%$ of them were male and $24 \%$ female). Most of the participants (54\%) has bachelor degrees in computer science or related disciplines and $32 \%$ had postgraduate degrees. Where $24 \%$ of the participants have worked with the Jordanian E-Gov project for more than four years, $41 \%$ of participants their experience in the Jordanian E-Gov project between two and four years, $22 \%$ of them for one to two years and $13 \%$ for less than one year. Most of the participants' roles were diverse with IT managers, E-Gov project managers and administrative development and training managers.

Most pf participants (67\%) approved that usability is an essential factor of success or failure of the whole E-Gov project, while $8 \%$ of participants has a contradictory opinion, and $25 \%$ of participants did not know a lot about usability. In the same study, a user perspective questionnaire has been modelled and distributed for 155 users to examine the usability of five E-Gov websites to show that $27 \%$ of the users believed about the difficulty of using the website to navigate and a bit confusing to follow. In addition, $19 \%$ of the users notified that the website does not supported with an effective search tool to facilitate their information acquirement. Moreover, $43 \%$ of users' participants believe that offering servicing tool such as FAQs and emails is insufficient to address the problem of information acquirement.

Number of studies such as $[22,28]$ discussed the best recommendations for better usability websites to include many factors like "Create accessibility aids to reduce confusion", "userfriendly interface" and "Have an online services menu". However, this paper objective is not to discuss or differentiate the usability criteria. But it is to show how still the Jordanian E-Gov websites having problems with the usability criteria and reflect that on the paper's objective. The paper's objective is to propose a prototype to overcome this problem with embedding a Conversational Agent into the E-Gov services and tools. Another factor that the Jordanian E-Gov websites suffer is the accessibility. The W3C (World Wide Web Consortium) defines the web accessibility as "people with disabilities can perceive, understand, navigate, and interact with the web, and they can contribute to the web" [29].Another definition to accessibility is to access a website anywhere and anytime from different platforms (wired and wireless devices) [30]. According to these definitions, anyone has the right to access and contribute to the web regardless of their machine, age (older people) or physical/ mental ability (such as blindness, low vision, deafness, hard of hearing).The Accessibility should modelled into a website to ensuring your website can be accessed equally in all machines/disability forms. According to [31, 32] "the accessibility is a subset of usability" which means the website that does not accessible from all people through different machines is not usable. The accessibility is a main crucial element that should be exist in E-Gov project to succeed [30].According to [10], 7\% of the evaluated Jordanian E-Gov websites (30 websites) were evaluated in terms of accessibility and their readiness to deliver online services worse than the standard global average.

Depending on the previous studies and results, it is clear that usability and accessibility factors into the E-Gov websites in Jordan need further development. However, this paper is not to 
discuss how to enhance these factors through the traditional ways. Instead, it introduce a new novel prototype by embedding an Arabic based Conversational Agent to facilitate users' services by chatting in Arabic with the proposed system instead of navigating among links. In addition, it is useful for disable people by voice chatting with the embedded CA as the next section explains.

\section{Applying an Arabic Based Conversational Agent into the Jordanian E-Gov}

As discussed above, the Jordanian E-Gov project still has number of weaknesses and it is faces number of challenges. In this paper, only two weaknesses have been discussed which are usability and accessibility to cover the paper's objectives. This paper suggests a novel idea to overcome these weaknesses by applying a prototype of an automatic chatting system with users called Conversational Agent (CA). A Conversational Agent is a smart system used to handle conversations between user and machine. Using the CA, a user can talk with a machine via textual or audible ways. Number of CAs has been built for many natural languages specially for English such as ELIZA [33], ALICE [34] and ADAM [35]. A few CAs has been built for Arabic language such as ArabChat [36]. CAs can be categorised into three main types; Linguistic CAs, Embodied CAs and the third type is mixing among them [36, 37].

The Embodied type has a humanoid character which handles the conversations using speech and body reactions such as: facial expressions, human sounds, and movement of the humanoid character eyes. Where, Linguistic CAs handle conversations using spoken and/or written methods [36]. The mixed approach can handle conversations using the two previous types' features [37].

CAs can be applied in many applications such as information retrieval, entertainment, business, education, e-commerce and help desk [36]. In this paper, the idea is to apply the CA into the EGovernment projects as well. Instead of wasting the user's time who targeting a service through an E-Gov website, simply, he/she can converse with the proposed CA to reach his/her targeted information. The CA can provide users with what he/she needs of information through chatting. In addition, the proposed CA can provide the user with the suitable link that target his/her service directly instead of navigating the website to find it. Then, the user simply click the provided link to start his/her service completion. The proposed CA is in Arabic to handle Arabic conversations for the Jordanian people through the official Jordanian E-Gov portal project. The proposed CA is linguistic based which means the Jordanian people will chat with the proposed CA using text based Arabic sentences. In addition, the proposed CA can handle spoken conversations to help disable people (ex. blind) using the E-Gov websites.

Generally, the CAs can be developed using number of approaches such as natural language processing, pattern matching and sentence similarity [36]. Each approach has advantages and disadvantages for a specific natural language. For instance, an approach is useful for English, it could be not useful for Arabic and vice versa. The natural language processing approach require full understanding for the sentence's structure which it is hard in Arabic processing as it is considered a Semitic language with very rich features [36, 38-40]. In addition, the computing cost using such approach is very high [36, 38, and 41].Moreover, this approach cannot handle Colloquial sentences which it is now profusely used by Arab people. Where, the pattern matching approach is simple as it depends on prepared list of patterns (regular expressions) that simulate the expected sentences to be matched [36, 42]. The pattern matching approach is not depend on a specific language which means the CA's engine could handle Arabic, English or Chinese sentences [36]. The only difference is different patterns for each natural language. In addition, the pattern matching approach has low computing cost[36].The pattern matching approach can handle any type of Arabic(classic, modern or colloquial) as Arab people nowadays use the colloquial type rather than the other types [36]. However, it require scripting large number of 
patterns to handle the expected conversations successfully. This weakness can be overcomes by different ways such as using the stemming technique for the patterns' keywords [43]. The last approach, sentence similarity, overcome the pattern matching problem (having large number of patterns) by having a very few number of patterns for each topic. This approach deals with Arabic semantic datasets such as "WordNet" to check the semantic similarity between words and between the competitor sentences. Finally, it will weight each pattern, and the highest weighted pattern, its response will be considered to the user. Generally, Arabic semantic datasets is still a young research area and needs further effort $[36,44]$. It is too risky to depend on this approach to build the proposed CA as the approach itself still needs time/effort to be structured well. In addition, to best of our knowledge, there is now study discussed the computing cost for such approach to compare it with other approaches. The computing cost factor in CAs building is very important as it working in an online environment with a huge number of expected users. As a result, it is not recommended to rely on this approach to build the proposed CA as it totally depends on building a rich well-structured dataset [36].Figure 3 considered a suggested example of user interface for the proposed prototype of CA.

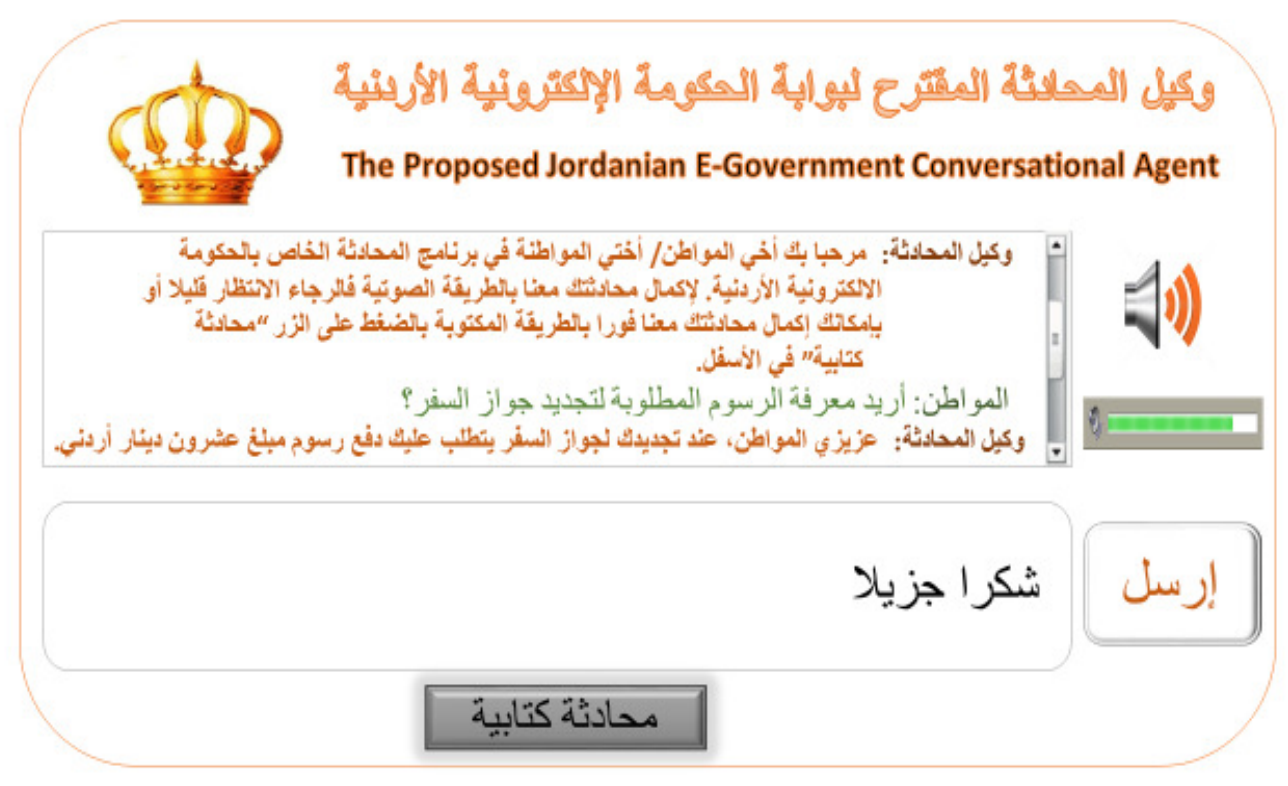

Figure 3: The Suggested user interface for the proposed CA.

Once a Jordanian citizen lunch the proposed CA through the E-Gov portal, the CA's interface will appear to user as illustrated in Figure 3. The proposed CA will start typing and speaking the same Arabic sentence (welcoming and introducing message) at the same time to make a choice for the user to choose either start chatting with typing or speaking. If the user like to continue chatting using the speaking way, he/she has to wait seconds without any actions and then start his/her conversations. Instead, if he/she like to start typing conversations, he/she can start it immediately by clicking the button that existed in the interface and labelled with "محادثة كتابية". The CA utterances/conversations and the user's conversations through the suggested interface are differentiated using different colours as appeared in the suggested interface (Figure 3).The proposed prototype can be applied for each E-Gov website alone or it can be for the whole E-Gov portal. Customizing number of CAs for number of Jordanian E-Gov websites might be better in terms of focusing on the scripted domain for each topic (a website service). Scripting the applied domain (E-Gov services) process is very important and needs effort as much as the decision maker want the conversations going successful to cover the most expected topics. Finally, if the 
user wants to terminate the conversations, simply, he/she can say 'bye' or close the conversation interface window.

\section{Conclusion}

The ICT sector in Jordan has been rapidly developed and has a special priority from the Jordanian government in the last two decades. This development includes number of sectors and the most important of them is the electronic government. The objective of the E-Gov project was to increase the overall government quality of services and improving its efficiency to satisfy users. The E-Gov program has been initiated in 2001 with a good steps at the initial stages. However, most of the Jordanian E-Gov websites are still considered in the informative stage. This means it still needs further effort and research to achieve its goals. This paper mentioned number of weaknesses and challenges that the Jordanian E-Gov faces. However, this paper illustrated only two weaknesses of the Jordanian government websites which are related to the usability and accessibility factors. Number of studies has been discussed these factors to show that the E-Gov websites has low level of usability and accessibility. As a result, when the websites become unusable that's might lead users to leave these websites and thus failing the whole E-Gov project. Instead, this paper proposed a prototype to increase the usability and accessibility of such websites by embedding a CA inside them. Using the proposed CA, a user can communicate with the E-Gov portal with spoken/written Arabic sentences. Using his/her natural language, a user will make his/her tasks successfully with the minimum time and effort instead of getting loss among links to find his/her service. In addition, the disable people will find a help using the proposed system by speaking with it to finish his/her request instead of asking help from others (undisabled) to do so.

\section{Acknowledgment}

The authors are grateful to the Applied Science Private University, Amman, Jordan, for the full financial support granted to this research.

\section{References}

[1] Fang, Z., "E-government in digital era: concept, practice and development". Journal of the Computer, 2002. Vol 10(2): p. 1-22.

[2] Yousef Elsheikh, Andrea Cullen, and D. Hobbs, e-Government in Jordan: challenges and opportunities. Transforming Government: People, Process and Policy, 2008. Vol. 2(2): p. 83-103.

[3] Nodou, V., "E-government for developing countries: opportunities and challenges". The Electronic Journal of Information Systems in Developing Countries (EJISDC), 2004. Vol 18(1): p. 1-24.

[4] Al-Shaka'a, S., Jordan e-Government Services, C.M.s. Head, Editor. 2011, (MoICT) Ministry of Information and Communications Technology: Amman.

[5] Technology, M.M.o.I.a.C., Jordan e-Government Program. 2006.

[6] UN, "UN Public Administration Programme (2010) United Nations e-government survey 2010". 2010.

[7] Btoush, M., "Evaluation of e-government services in Jordan: providers \& users' perceptions". 2009, Sheffield Hallam University: UK.

[8] AlFawwaz, B., Evaluation of eGovernment Websites Usability in Jordan, in School of Engineering and Design. 2011, Brunel University: London. p. 189.

[9] Gil-García, J. and A. Pardo, "E-government success factors: Mapping practical tools to theoretical foundations". Government Information Quarterly, 2005. Volume 22(2): p. 187-216.

[10] Al-Soud, A.R. and K. Nakata. Evaluating e-government websites in Jordan: Accessibility, usability, transparency and responsiveness. in Progress in Informatics and Computing (PIC), 2010 IEEE International Conference on. 2010. Shanghai: IEEE. 
[11] Al-Omari, H., E-Government Architecture In Jordan: A Comparative Analysis. Journal of Computer Science, 2006. Vol 2(11): p. 846-852.

[12] Abran, A., et al., "Usability Meanings and Interpretations in ISO Standards". Software Quality Journal, 2003. Volume 1(4): p. pp. 325-338.

[13] Cappel, J. and Z. Huang, "A usability analysis of company websites". The Journal of Computer Information Systems, 2007. Volume 48(1): p. pp. 117-123.

[14] Nielsen, J. (2003) "Usability 101: Introduction to Usability". Volume,

[15] Nielsen, J., Designing Web Usability: The Practice of Simplicity. 2000, USA: New Riders Publishing.

[16] Van Welie, M., G. van der Veer, and A. Eliëns, "Breaking down Usability", in Proceedings of Interact '99. 1999: Edinburgh, Scotland.

[17] Thompson, K.M., C.R. McClure, and P.T. Jaeger, "Evaluating federal websites: Improving eGovernment for the people". Computers in society: Privacy, ethics, and the Internet, 2003.

[18] Casaló, L., C. Flavián, and M. Guinaliú, "The role of accessibility and commitment in the development of an e-government strategy", in eGovernment Workshop "05 (eGOV05) 2005: Brunel University, West London, UK.

[19] Stanziola, E., et al., "Hidden Negative Social Effects of Poor eGovernment Services Design". Springer-Verlag Berlin Heidelberg, EGOV 2006, LNCS 4084., 2006: p. pp.150-161.

[20] Al Shafi, S. and V. Weerakkody, "Implementing and Managing E-Government in the State of Qatar: A Citizens Perspective". Electronic Government: An International Journal., 2007. Vol 4(4): p. pp. 436-450.

[21] Donker-Kuijer, M., M. Jong, and L. Lentz, "Usable guidelines for usable websites: an analysis of five e-government heuristics”. Government Information Quarterly, 2010. Vol 27: p. pp. 254-263.

[22] Al Osaimi, O. and A. AlSumait, Usability Guidelines for Arab E-government Websites. International Journal of Social, Education, Economics and Management Engineering., 2013. Vol:7(12).

[23] Pearrow, M., "Website Usability Handbook". InterCity Press, Rockland, MA., 2000.

[24] Choudrie, J., J. Wisal, and G. Ghinea, "Evaluating the usability of developing countries' egovernment sites: a user perspective". Electronic Government, an International Journal, 2009. Volume 6 (3): p. pp. 265-281.

[25] Holzer, M. and S.T. Kim, "Digital Governance in Municipalities Worldwide (2007), A Longitudinal Assessment of Municipal Web Sites Throughout the World". The E-Governance Institute, Rutgers University, Newark and the Global e-policy e-government Institute, Sungkyunkwan, University., 2007.

[26] Mofleh, S., "Managing e-government projects: the gap between supply and demand". 2008, Bristol University: UK.

[27] Baker, D., "E-government: website usability of the most populous counties". 2004, Arizona, State University: USA.

[28] West, D.M. “Global E-Government, 2007”. in Proceedings of the 5th International Conference on eGovernment. 2007. USA: Providence: Centre for Public Policy, Brown University.

[29] Consortium), W.C.W.W.W. Web Accessibility Initiative 2015 [cited 2015; Available from: http://www.w3.org/standards/webdesign/accessibility.

[30] Abanumy, A., A. Al-Badi, and P. Mayhew, "e-government Website Accessibility: In-Depth Evaluation of Saudi Arabia and Oman”. The Electronic Journal of e-government, 2005. Vol. 3(3): p. pp. 99-106.

[31] Brajnik, G. Automatic web usability evaluation: what needs to be done? in In Proc. 6th Conference on Human Factors and the Web. 2000. Austin, Texas, United States.

[32] Krug, S., Don't make me think: a common sense approach to web usability. 2nd edition ed. 2006, California, United States.: New Riders Press.

[33] Weizenbaum, J., ELIZA: A computer program for the study of natural language communication between man and machine. Communications of the ACM., 1966. Vol 10.: p. PP 36-45.

[34] Wallace, R.S. ALICE: Artificial Intelligence Foundation Inc. 2008 [cited; Available from: http://www.alicebot.org.

[35] ConvAgent. ConvAgent Foundation- ADAM Conversational Agent. 2015 [cited; Available from: www.ConvAgent.com.

[36] Hijjawi, M., et al. ArabChat: An Arabic Conversational Agent. in Computer Science and Information Technology (CSIT), 2014 6th International Conference on. 2014. Amman, Jordan. 
[37] O’Shea, K., Z. Bandar, and K. Crockett. A Novel Approach for Constructing Conversational Agents using Sentence Similarity Measures. in Proceedings of the World Congress on Engineering Vol I, WCE 2008. 2008. London, U.K.

[38] Ali, F. and S. Khaled, Arabic Natural Language Processing: Challenges and Solutions. 2009. 8(4): p. $1-22$.

[39] Al-Shammari, E., Improving Arabic text processing via stemming with application to text mining and Web retrieval, in Graduate Faculty. 2010, George Mason University. p. 201.

[40] Diab, M., K. Hacioglu, and D. Jurafsky, Automatic tagging of Arabic text: from raw text to base phrase chunks, in Proceedings of HLT-NAACL 2004: Short Papers. 2004, Association for Computational Linguistics: Boston, Massachusetts.

[41] Habash, N., Introduction to Arabic Natural Language Processing, ed. U.o.T. Graeme Hirst. 2010: Morgan \& Claypool.

[42] Sammut, C. and D. Michie, InfochatTM Scripter's Manual, Convagent Ltd. 2001: Manchester.

[43] Hijjawi, M., et al., An Application of Pattern Matching Stemmer in Arabic Dialogue System, in 5th International KES Conference on Agents and Multi-agent Systems - Technologies and Applications. 2011: Manchester.

[44] Almarsoomi, F., et al., ArabicWord Semantic Similarity. World Academy of Science, Engineering and Technology 2012. Vol:6.

\section{Authors}

Dr. Mohammad Hijjawi is currently an assistant professor at the Applied Science University in Amman, Jordan. Dr. Hijjawi holds a Ph.D. degree in Computer Science from Manchester Metropolitan University, UK. His research interests include: Conversational Agents, machine learning, Data Mining and Arabic language processing.

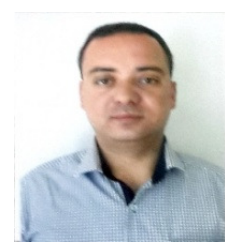

Dr. Hesham Abusaimeh received his B.Sc. in Computer Science from Applied Science University (ASU), Amman, Jordan in 2003, and M.Sc. in Computer Science from New York Institute of Technology (NYIT) in 2004, both in Computer Science. Dr. Abusaimeh's Ph.D. degree is in Computer Science in the field of Wireless Sensor Networks communication and routing protocols from Loughborough University, UK in 2009. Dr. Abusaimeh used to be web application programmer using ASP.net with C\# and SQLServer databases. Dr. Abusaimeh's research interests include Cloud Computing, Virtualization, Network and Controls, Routing Protocols, Network Lifetime and Consumption Energy, Wireless Sensor Networks, and Web Applications Security. Nowadays, Dr. Hesham Abusaimeh is an Associate Professor in the Computer Science Department at the Applied Science University, Amman, Jordan. 